other at concentrations of 10,20 and $50 \mu \mathrm{g} / \mathrm{ml}$. The low binding of SP in human plasma suggests there is a low potential for a protein binding interaction between A77 1726 and SP over the range of concentrations examined. A clinical study to investigate the pharmacokinetics of A77 1726 and SP in healthy subjects is underway.

\section{THU0194 DIGITAL VASCULITIS IN A PATIENT WITH RHEUMATOID ARTHRITS: GOOD RESPONSE ON ANTI-TNF BLOCKADE}

FH Van den Hoogen, MM Zandbelt, A Den Broeder, LB Van de Putte. Rheumatology, University Medical Center, Nijmegen, Netherlands

\subsection{6/annrheumdis-2001.1096}

Background Rheumatoid arthritis (RA) may be complicated by vasculitis. Vasculitis usually affects small vessels of the skin causing nailfold infarcts, but may also affect larger vessels and cause severe damage to internal organs. In such cases, treatment with high doses of corticosteroids or other immunosuppressive drugs may be necessary. TNF-alpha blockade has been shown to be an effective and safe treatment for RA, but thus far no reports have addressed the effect of TNF-alpha blockade on extra-articular manifestations of RA, such as vasculitis.

Objectives We report a patient with RA and nailfold infarcts which repeatedly disappeared for several weeks following monthly i.v. injections with an anti-TNF alpha receptor fusion protein.

Methods A 46 year old woman was diagnosed as having rheumatoid factor positive, erosive RA in 1982. Due to the uncontrollable disease she was included in 1994 in a study with Ro 45 2081, a fusion protein combining two p55 TNF receptors with the Fc component of an IgG human antibody (Roche, Basel, Switzerland, sTNFR:Fc). After a three months placebo controlled phase she was treated with $50 \mathrm{mg}$ sTNFR:Fc every four weeks.

Results Clinical response was impressive with swollen joint counts decreasing from 32 to 5 and C-reactive protein CRP levels declining from 95 at baseline to 20 after the first injection. Low disease activity was sustained for the following years. Besides sTNFR:Fc her medication consisted of oral prednisone 5 $\mathrm{mg}$ a day and occasionally paracetamol $500 \mathrm{mg}$. In the spring of 1999 she first noticed nailfold infarcts on the fingers of both hands. These lesions disappeared after every injection of sTNFR: $F_{c}$ and reappeared three weeks thereafter when the clinical effects of sTNFR:Fc were decreasing. This effect on the digital vasculitis has been well documented during several cycles of sTNFR:Fc administration.

Conclusion The prompt disappearance of nailfold infarcts after sTNFR:Fc administration observed in our patient strongly suggests a therapeutic effect of sTNFR:Fc on active vasculitis. This observation raises the question whether blocking of TNF-alpha might also be effective in more severe forms of vasculitis and possibly other extra-articular manifestations of RA, some of which are life threatening and are currently treated with high doses of corticosteroids and immunosuppressive drugs.

\section{THU0195 INTRA-MACHINE AND INTRA-READER AGREEMENT OF RA DISEASE ACTIVITY AND DAMAGE USING MRI. COMPARISON WITH CLINICAL AND LABORATORY MEASURES}

P Bird, M Lassere. Rheumatology, St George Hospital, Sydney, Australia

10.1136/annrheumdis-2001.1097

Background Magnetic resonance imaging offers a direct means of evaluating inflammation disease activity and damage in rheumatoid arthritis joints. However, few studies have evaluated intra-machine MRI. ${ }^{1}$

Objectives Evaluate the agreement of intra-machine MRI using the OMERACT 5 Rheumatoid Arthritis MRI Score (Om5 RAMRIS) ${ }^{2}$ and compare MRI reliability to clinical and laboratory measures.

Methods 12 subjects with seropositive RA, median disease duration 6 years, were chosen to reflect spectrum of RA severity. MRI was performed at same time of day at baseline and $48 \mathrm{~h}$. All sources of variability were either controlled or measured. A cannula was inserted into the nondominant arm and serum was collected prior to MR for ESR/CRP. The cannula was left insitu for administration of gadolinium (Gd). MRI of wrist was performed with dominant hand splinted in semipronated position alongside the body. Axial and coronal images were obtained preGd using T1, proton density and T2 (FS) sequences. Gadolinium was administered at $0.1 \mathrm{mmol} / \mathrm{kg}$ over 90 secs. Post Gd fat suppressed sequences commenced 2 min post injection (axial then coronal). MRI images were read in random order by a single blinded observer using the Om5 RAMRIS. All images were reread in random order at $48 \mathrm{~h}$ by same observer. Additional clinical data at baseline and $48 \mathrm{~h}$ : HAQ, SF36, 28 swollen and tender joint count (same observer).

Results Intra-machine MRI (ie at baseline and $48 \mathrm{~h}$ ) intraclass correlation coefficients (ICCs) were lower for all measures of disease activity (synovitis global, synovial maximal thickness and bone oedema) than for lesions of disease damage (bone erosions and bone defects). ICCs of summated wrist activity score for intra-machine MRI were $0.53-0.70$, whereas intra-reader ICCs were 0.86 and 0.90 . However ICCs of summated wrist damage score for intra-machine MRI were $0.89-0.96$ and for intrareader were 0.93 and 0.97 . Mean (SD) scores at baseline and 48 hrs. ICCs for clinical and laboratory data were: DAS28 $=0.94$, $\mathrm{HAQ}=0.96, \mathrm{TJC}=0.89, \mathrm{ESR}=0.76, \mathrm{SJC}=0.72$ and $\mathrm{CRP}$ $=0.55$. Mean differences at baseline and $48 \mathrm{hrs}$ for all clinical, laboratory and MRI measures were not statistically significant. Furthermore, none of the differences consistently reflected either an increase or decrease in disease activity. Smallest detectable difference (SDD) for selected measures were as follows: wrist activity $\pm 35(50 \%$ of score range $(\mathrm{SR}))$, wrist damage $\pm 18(15 \%$ SR), DAS28 土. 98 (23\% SR), HAQ \pm .49 (21\% SR), SJC \pm 5.4 $(57 \% \mathrm{SR}), \mathrm{TJC} \pm 5.2(35 \% \mathrm{SR})$ and $\mathrm{CRP} \pm 10(71 \% \mathrm{SR})$.

Conclusion Intra-reader agreement using the OMERACT 5 Rheumatoid Arthritis MRI Score has excellent intra-reader agreement for the assessment of synovitis, bone oedema, bone erosions and defects. Intra-machine agreement at $48 \mathrm{~h}$ was also excellent for bone erosions and defects and the SDD was quite acceptable. Lower ICCs for measures of MRI RA activity probably reflect underlying true variability in disease activity even at $48 \mathrm{~h}$ (suggested by variability in CRP), as well as a component of measurement error, (implied by relative stability of DAS28). Thus to disentangle the discrimination (reliability vs responsiveness) of this MRI activity scoring system, it requires further evaluation in a RCT. 


\section{REFERENCES}

1 Lassere $\mathrm{M}$, et al. J Rheum, in press

2 Conaghan $\mathrm{P}$, et al. J Rheum, in press

\section{THU0196 EFFICACY OF AND PREDISPOSING FACTORS FOR RESPONSE TO LEFLUNOMIDE (LEF) IN PATIENTS WITH RHEUMATOID ARTHRITIS (RA)}

${ }^{1} \mathrm{M}$ Dougados, ${ }^{2} \mathrm{C}$ Antoine, ${ }^{2} \mathrm{~S}$ Brin, ${ }^{3} \mathrm{P}$ Emery, ${ }^{4} \mathrm{EM}$ Lemmel, A Rodriguez de la Serna ${ }^{5}$, CA Zerbini', ${ }^{5} \mathrm{P}$ Van Riel. ${ }^{1}$ Rene Descartes University, Hospital Cochin, Paris, France; ${ }^{2}$ Laboratoire Aventis, Paris, France; ${ }^{3}$ University of Leeds Research School of Medicine, Leeds, UK; ${ }^{4}$ Max Grundig Clinic, Buhl, Germany; ${ }^{5}$ University Medical Centre Nijmegen, Nijmegen, The Netherlands; ${ }^{5}$ San Pablo Hospital, Barcelona, Spain; ${ }^{6}$ Hospital Heliopolis, Sau Paulo, Brazil

\subsection{6/annrheumdis-2001.1098}

Background LEF is a new DMARD for the treatment of active RA in adults. Large phase III clinical trials have shown that LEF significantly improves the signs and symptoms of RA compared to placebo. LEF also significantly improved patient functional ability and individual health-related quality of life compared with placebo and methotrexate, and slowed radiographically assessed disease progression. In addition, LEF has an early onset of action, with a clinical response being seen by 4 weeks and a sustained response observed at up to 2 years.

Objectives To evaluate the efficacy of, and predisposing factors for response to LEF in a large multinational, multicenter, openlabel cohort study at 24 weeks.

Methods Patients with active RA classified by a disease activity score (DAS >3.2) were enrolled and treated with LEF (100 mg loading dose $\mathrm{x} 3$ days with $20 \mathrm{mg}$ QD thereafter). The efficacy variables analysed at week 24 were the DAS 28 responder rate, the response rate according to ACR 20\%, ACR 50\% and ACR $70 \%$, and change from baseline for both scores. All subjects who received at least one dose of study medication were included in the intent-to-treat with last observation carried forward analysis. At week 24, baseline data (including RA duration and ARA functional class) from patients who were classified as responders compared with non-responders at week 24 were analysed to determine predictive factors of response.

Results Of the 966 patients treated with LEF for 24 weeks, 720 (75\%) were female with a mean age of 55 years (range 19?75). The mean duration of previous RA was 7.5 years with $62 \%$ patients first being diagnosed $>2$ years. The mean duration of morning stiffness was $2.1 \mathrm{~h}$ and $83 \%$ of patients tested positive for rheumatoid factor at baseline. For those patients who had previously had DMARD treatment $(72 \%)$, the mean number of previous treatments was 2.6 . At week $24,78 \%$ of patients were responders according to the DAS 28 responder rate. The percentage of patient responders at week 24 for ACR 20\%, ACR $50 \%$ and ACR $70 \%$ were 67,36 , and $10 \%$ respectively. At week 24, 13\% patients fulfilled the disease remission criteria (DAS 28 $<=3.2$ ). Of the patients, $35 \%$ and $50 \%$ were responders at week 4 and 8, respectively, and maintained efficacy until week 24 . One hundred and ninety patients were withdrawn from the study (11\% due to an adverse event, $3 \%$ for a lack of efficacy). ARA functional class 1 and RA duration $>2$ years were identified as predisposing factors for treatment response.

Conclusion This study confirms the efficacy of LEF in patients with RA. Further evaluation may suggest the clinical relevance of identified predisposing factors for treatment response.

\section{THU0197 TUMOUR-ASSOCIATED ANTIGENS IN RHEUMATOID ARTHRITIS}

IP Athanassiou, 'A Elezoglou, ${ }^{2}$ Kostoglou-Athanassiou, 'A Theodorou, ${ }^{1} \mathrm{P}$ Konstantopoulou, ${ }^{1} \mathrm{~A}$ Kotrotsios, ${ }^{3} \mathrm{P}$ Dimou, ${ }^{1} \mathrm{G}$ Vezyroglou. ${ }^{1}$ Department of Rheumatology; ${ }^{2}$ Department of Endocrinology, Metaxa Hospital, Pireaus, Greece; ${ }^{3}$ Department of Biochemistry, Asklepieion Hospital, Voula, Athens

10.1136/annrheumdis-2001.1099

Background Rheumatoid arthritis (RA) is characterised by aberrations of the immune system. Moreover, treatment of RA patients involves agents, which induce immunosuppression. However, it has not yet been clarified whether RA or its primary treatment predispose to the development of malignancy.

Objectives The aim was to investigate tumour-associated antigens and other markers of malignancy in patients with RA.

Methods Patients with RA, $\mathrm{n}=38$, aged $59.0 \pm 2.0$ years (mean \pm SEM), duration of disease $8.1 \pm 1.1$ years were studied. Patients with osteoarthritis (OA), $\mathrm{n}=38$, were also studied. None of the patients had any known malignancy. All patients had a complete physical examination when entering the study. In all patients levels of haematocrit, haemoglobin, erythrocyte sedimentation rate, C-reactive protein, rheumatoid factor and alkaline phosphatase were measured. All patients were tested for positivity for antinuclear antibodies (ANA). In all patients levels of carcinoembryonic antigen (CEA), a-fetoprotein, b2microglobulin, CA 15 - 3, CA 125 and CA 19 - 9 were measured.

Results In patients with RA haematocrit was $35.3 \pm 0.5 \%$ (mean \pm SEM), haemoglobin $11.2 \pm 0.2 \mathrm{~g} / \mathrm{dl}$, C-reactive protein 54.7 $\pm 6.5 \mathrm{mg} / \mathrm{l}$ and rheumatoid factor $197.6 \pm 34.9 \mathrm{iu} / \mathrm{ml}$. In patients with OA haematocrit was $39.0 \pm 0.7 \%$, haemoglobin $12.4 \pm 0.2 \mathrm{~g} / \mathrm{dl}$, C-reactive protein $23.4 \pm 4.9 \mathrm{mg} / \mathrm{l}$ and rheumatoid factor $10.6 \pm 0.2 \mathrm{iu} / \mathrm{ml}$. In patients with RA and OA CEA levels were $1.4 \pm 0.1 \mathrm{ng} / \mathrm{ml}$ and $2.2 \pm 0.2 \mathrm{ng} / \mathrm{ml}$, respectively (normal range $<5.0 \mathrm{ng} / \mathrm{ml}$, Student's t test $\mathrm{p}<0.05$ ). In RA and OA patients a-fetoprotein levels were $3.1 \pm 0.2 \mathrm{ng} / \mathrm{ml}$ and 4.0 $\pm 0.3 \mathrm{ng} / \mathrm{ml}$, respectively (normal range $<8.6 \mathrm{ng} / \mathrm{ml}$ ). In RA and OA b2-microglobulin levels were $1.7 \pm 0.1 \mathrm{mg} / \mathrm{l}$ and $1.6 \pm 0.1$ $\mathrm{mg} / \mathrm{l}$, respectively. There was no difference in the levels of any of the specific tumour-associated antigens between the groups of patients with RA and OA. In RA and OA patients CA $15-3$ levels were $19.1 \pm 0.8 \mathrm{u} / \mathrm{ml}$ and $18.2 \pm 1.0 \mathrm{u} / \mathrm{ml}$, respectively (normal range $<28 \mathrm{u} / \mathrm{ml}, \mathrm{p}>0.05$ ). In RA and OA patients CA 125 levels were $9.5 \pm 0.9 \mathrm{u} / \mathrm{ml}$ and $7.0 \pm 0.5 \mathrm{u} / \mathrm{ml}$, respectively (normal range $<35 \mathrm{u} / \mathrm{ml}, \mathrm{p}>0.05$ ). In RA and OA CA $19-9$ levels were $9.3 \pm 1.4 \mathrm{u} / \mathrm{ml}$ and $9.7 \pm 1.3 \mathrm{u} / \mathrm{ml}$, respectively (normal range $<37 \mathrm{u} / \mathrm{ml}, \mathrm{p}>0.05$ ).

Conclusion In RA patients CEA levels were found to be lower than those of OA patients, being however in the normal range for both groups. Levels of tumour-associated antigens were found to be in the normal range in RA and OA patients, no significant difference being observed between the groups. It appears that in RA no significant alteration of the levels of tumour-associated antigens is observed. Additionally, in the population of patients studied RA did not appear to predispose to the development of malignancy. More studies are needed in order to find the effect of RA and its primary treatment on the development of malignancy. 